\title{
Primary Renal Squamous Cell Carcinoma: An Unusual Malignancy
}

\author{
Huma Mushtaq ${ }^{1}$, Naima Tariq ${ }^{2}$, Tehreem Atif ${ }^{3}$, Saeed Alam ${ }^{4}$, Mumtaz Ahmad 5 \\ ${ }^{1}$ Associate Professor, Department of Pathology, Islamabad Medical and Dental College \\ ${ }^{2}$ Assistant Professor, Department of Pathology, Islamabad Medical and Dental College \\ ${ }^{3}$ Senior Lecturer, Department of Pathology, Islamabad Medical and Dental College \\ ${ }^{4}$ Professor, Department of Pathology, Islamabad Medical and Dental College \\ ${ }^{5}$ Professor, Department of Urology, Islamabad Medical and Dental College
}

\begin{abstract}
A B S T R ACT
Malignancies of the upper urinary tract are rare, accounting for about $8 \%$ of all malignancies of the renal system, presenting mostly as urothelial carcinoma. Squamous cell carcinoma (SCC) arising from the upper urinary tract is even more rare, accounting for about $0.5 \%$ of all malignancies of the renal system and $10 \%$ of all renal pelvic tumors. There are very few case reports in the indexed literature regarding renal squamous cell carcinoma. Here we present a case of SCC arising from the lower pole of left kidney, in a 35-year-old male resident of Muzaffarabad, Azad Kashmir.

Key Words: Squamous cell carcinoma, Kidney, Hydronephrosis

Correspondence:

Huma Mushtaq

Article info:

Email: huma.mushtaq@imdcollege.edu.pk

Received: February 15, 2019

Cite this case Report: Mushtaq H, Tariq N, Atif T, Alam S, Ahmed M. Primary Renal Squamous Cell Funding Source: Nil

Carcinoma: An Unusual Malignancy. J Islamabad Med Dental Coll. 2019; 8(1):50-53

Conflict of Interest: Nil
\end{abstract}

\section{Introduction}

Malignancies of the upper urinary tract are rare and account for almost $8 \%$ of all malignancies of renal system, presenting mostly with the histological type of urothelial carcinoma. Squamous cell carcinoma (SCC) arising from the upper urinary tract is even more rare, accounting for only $0.5 \%$ of all malignancies of the renal system and $10 \%$ of all renal pelvic tumors. ${ }^{1}$ SCC arising from the upper urinary tract is a more aggressive tumor as compared to the common histological types, and it is clinically diagnosed at a later stage. ${ }^{2}$ Primary SCC presents mostly in an age group of 50-70 years and is slightly more common in females.

Histopathologically, SCC of kidney is similar to SCCs of other sites and it comprises of keratin pearls along with atypical squamoid cells and keratotic cellular debris in the background. Radiologic examination reveals a variety of presentation of SCC of kidney. It may present as a solid mass along with hydronephrosis and calcifications, or there may be an infiltrative lesion without any distinct margins. It may present as a nonfunctioning kidney having renal calculi or it may even present as a lowdensity mass arising from renal parenchyma. ${ }^{3}$ Although the exact cause of squamous cell carcinoma of kidney is unknown, there are certain etiological factors that are associated with its occurrence such as infections, renal calculi, chemicals, vitamin A deficiency and hormonal imbalance. ${ }^{4}$

According to previous research, this process initiates as urothelial metaplasia occurring secondary to chronic irritation and it further leads to dedifferentiation, dysplasia and finally development of SCC .5 These tumors are treated by aggressive surgical efforts, but even then the prognosis is poor and mostly the patients die after one year of surgical treatment. ${ }^{6}$ There are very few case reports in the literature regarding renal squamous cell carcinoma, we thus presented with a case of SCC arising from the lower pole of left kidney in a 35 year old male, resident of Muzaffarabad, Azad Kashmir. 


\section{Case Report}

A 35-year-old, chronic smoker, resident of Muzaffarabad, Azad Kashmir presented in the Out Patient of Urology Department of Akbar Niazi Teaching Hospital (ANTH) with complaint of on and off fever and vomiting for the past 1 month. He also had left lower quadrant pain in abdomen for the last six months. Initially he went to local clinics and took antibiotics, however there was no relief. There was no history of weight loss or hematuria. Ultrasound examination performed at an outside clinic revealed a grossly enlarged kidney with multiple calculi, dilated pelvicalyceal system and marked thinning of cortex. Computed tomography of kidneys, ureters and bladder (CT KUB) revealed a suspected neoplastic/ infective mass in the lower pole of left kidney, hydronephrosis, along with perinephric fat stranding. No normal renal parenchyma was identified. Ureters appeared normal in size, shape and position.

An open nephrectomy was performed and specimen was sent for histopathological evaluation. Gross examination revealed single enlarged left kidney along with the ureter. Cut surface of the kidney showed a large tumor almost completely replacing the renal parenchyma. The tumor measured $10 \times 9.0 \mathrm{~cm}$ and had ruptured through the outer surface of the nephrectomy specimen. It was grey-white and friable in appearance. Moreover, multiple renal calculi were also found (Figure 1) Microscopic examination showed an infiltrative tumor comprising of nests and cords of atypical squamoid cells with keratin pearl formation. Extensive sampling was performed; however, no urothelial component was found within the tumor. Few residual tubules and glomeruli were also identified. Proximal ureter margin along with outer renal capsule were involved by tumor however distal ureteric margin was uninvolved. It was labeled as well differentiated squamous cell carcinoma (Figures 2 and 3 ).

On follow up at six weeks, the bone scan of the patient was negative. Bone marrow aspiration and trephine biopsy showed no evidence of infiltration by the tumor. Ultrasound KUB showed development of irregular thick wall hypoechoic collection suggestive of abscess in left renal area. Surgical clearing of the area was done and tissue was sent for a histopathological opinion. Microscopic examination showed fragments of tumor with similar morphology as seen in nephrectomy specimen, therefore representing remnants of squamous cell carcinoma.

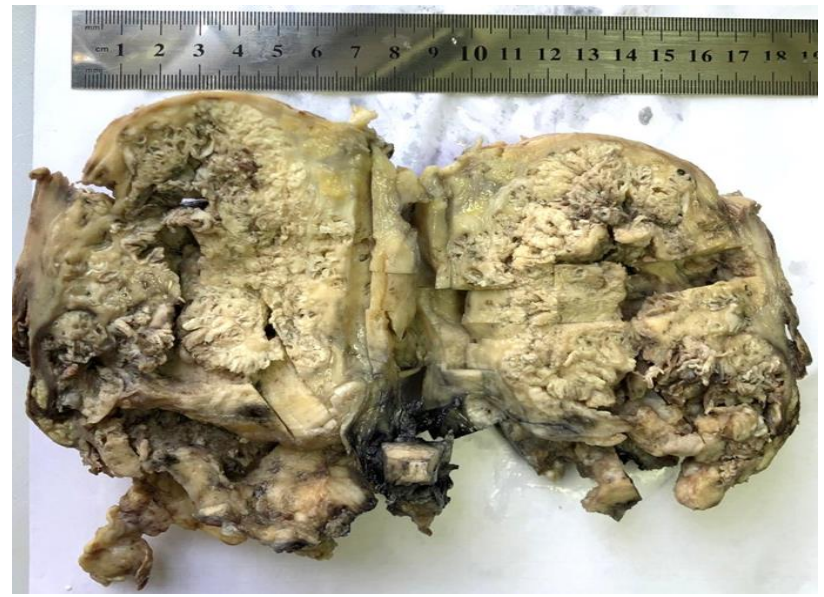

Figure 1: Grossly enlarged kidney along with ureter. Cut surface shows a large tumor almost completely replacing the renal parenchyma, grey-white and friable in appearance

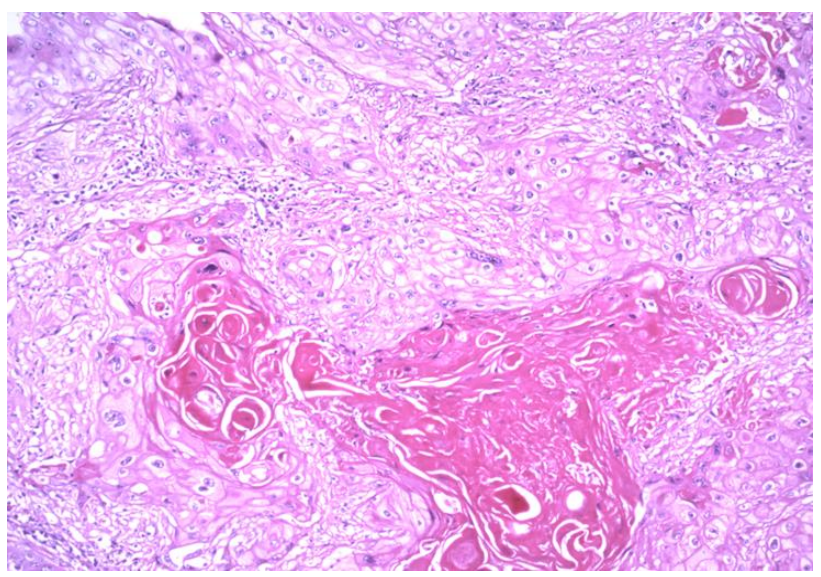

Figure 2: Microscopic examination shows an infiltrative tumor comprising of nests and cords of atypical squamoid cells with keratin pearl formation (10 $\mathrm{x}$ magnification)

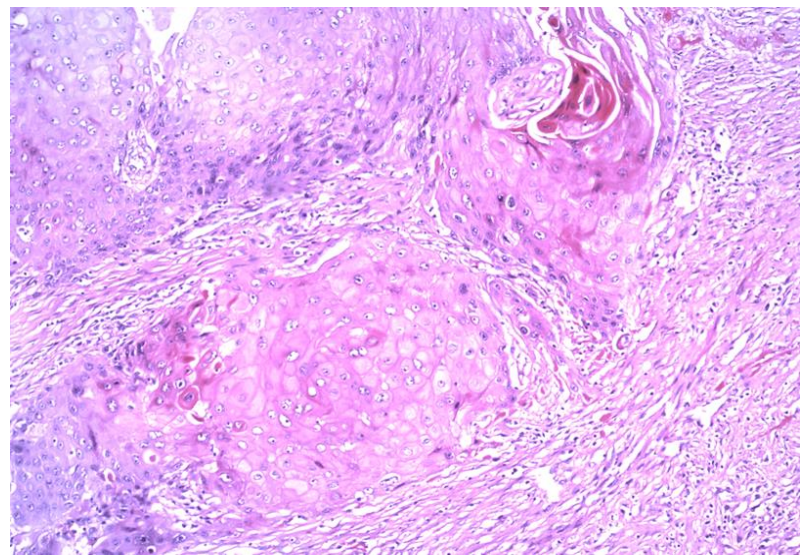

Figure 3: Microscopic examination shows SCC with individual cells exhibiting pleomorphism along with high N/C ratio and hyperchromatic nuclei (10 $\mathrm{x}$ magnification) 


\section{Discussion}

Squamous cell carcinoma arising from the kidney is a very rare and unusual tumor and it usually arises from the collecting system. ${ }^{7}$ Renal squamous cell carcinoma usually presents as a high-grade tumor and therefore it is more aggressive. Transitional cell carcinoma is the commonest histological type among the tumors arising from renal pelvis and this is followed by SCC which is a very rare entity. ${ }^{8}$ Histopathologically, the features of SCC of kidney are the same as SCCs arising from other areas, the microscopic features such as intercellular bridges, keratin pearls and keratotic cellular debris are present. Metastasis from other sites should be carefully ruled out before labeling it as primary renal SCC and despite rest of the findings there should be normal histopathology of the renal pelvis. ${ }^{9}$ As compared to other malignancies of the upper urinary tract, SCC is more aggressive presenting as a high grade tumor with a poor prognosis. ${ }^{10}$ Similar to other organs, conditions like inflammation, chronic irritation and infection are thought to develop squamous metaplasia in the urothelium present in the renal collecting system and this may further progress to dysplasia or even carcinoma in some patients. ${ }^{3}$

According to previous studies, the mean age of patients presenting with SCC of renal pelvic area is around 56 years and usually there is no predilection for laterality or sex. ${ }^{6}$ In this case, the patient was a young male, aged 35 years, and tumor was present in the left kidney. This tumor usually arises from the urinary bladder, sometimes from the male urethra but very rarely from the renal pelvis. In patients presenting with this tumor, features of paraneoplastic syndromes have also been observed such as leukocytosis, hypercalcemia and thrombocytosis. Previously $84 \%$ of renal SCC presented as locally advanced or metastatic tumor. ${ }^{11}$ Various etiological factors have been associated with the pathogenesis of SSC of upper urinary tract but the strongest association has been noted with renal calculi. In the previously reported cases, up to $100 \%$ of renal SCC cases had nephrolithiasis. ${ }^{6}$ In this case, multiple renal calculi were also present.

The radiologic findings of SCC of kidney vary from case to case. In this case, plain CT KUB was done and revealed a mass in lower pole of left kidney, hydronephrosis and perinephric fat stranding. In a study done by Lee et al., the main two features of renal SCC noticed on CT scan imaging were of enhancing extra luminal or exophytic mass and intraluminal component in some cases. ${ }^{12}$ This type of malignant tumor generally has a poor prognosis mainly because it usually presents at an advanced stage and therefore surgical resection along with adjuvant chemoradiotherapy is not so effective. In this condition, 5year survival rate is usually less than $10 \% .^{13,14,15}$ On the basis of extent of primary tumor invasion, involvement of regional lymph nodes by the tumor and evaluation of distant metastasis radiologically, staging of this tumor is done. ${ }^{3}$

The renal pelvic SCC is treated mainly by performing nephrectomy and urethrectomy may or may not be done. In metastatic cases, platinum-based chemotherapy is given along with radiotherapy but nephrectomy is also done to confirm the histopathologic diagnosis. Methotrexate, cisplatin and bleomycin is given in combination to treat renal SSC but it has failed to give survival benefit to the patients. ${ }^{16}$

\section{Conclusion}

Squamous cell carcinoma arising from the upper urinary tract region is very rare. It is usually detected when it has become locally advanced or has metastasized. Possibility of renal squamous cell carcinoma should be kept in mind while evaluating upper urinary tract tumors, especially in cases having the above mentioned risk factors. In order to make an accurate diagnosis a detailed history should be taken along with proper imaging and histopathological evaluation. These tumors are treated aggressively by surgical resection and chemoradiation is given in patients having a metastatic tumor.

\section{References}

1. Busby JE, Brown GA, Tamboli P, Kamat AM, Dinney CP, Grossman HB et al. Upper urinary tract tumors with nontransitional histology: a single-center experience. Urology. 2006; 67(3):518-23.

2. Lee TY, Ko SF, Wan YL, Cheng YF, Yang BY, Huang DL et al. Renal squamous cell carcinoma: CT findings and clinical significance. Abdominal imaging. 1998; 23(2):203-8. 
3. Nachiappan M, Litake MM, Paravatraj VG, Sharma N, Narasimhan A. Squamous cell carcinoma of the renal pelvis, a rare site for a commonly known malignancy. Journal of Clinical and Diagnostic Research: JCDR. 2016; 10(1): PD04.

4. Talwar N, Dargan P, Arora MP, Sharma A, Sen AK. Primary squamous cell carcinoma of the renal pelvis masquerading as pyonephrosis: A case report. Indian journal of pathology \& microbiology. 2006; 49(3):418-20.

5. Mardi K, Kaushal V, Sharma V. Rare co-existence of keratinizing squamous cell carcinoma with xanthogranulomatous pyelonephritis in the same kidney: Report of two cases. J Cancer Res Ther. 2010; 6: 339-41.

6. Holmang S, Lele SM, Johansson SL. Squamous cell carcinoma of the pelvis and ureter: Incidence, symptoms, treatment and outcome. J Urol. 2007; 178: 51-56

7. Odabap Ö, Karakök M, Yýlmaz Y, Atilla MK, Akman E, Aydýn S. Squamous cell carcinoma of the kidney. Eastern Journal of Medicine. 2000; 5(1): 35-6.

8. Mizusawa $\mathrm{H}$, Komiyama I, Ueno $\mathrm{Y}$, Maejima $\mathrm{T}$, and Kato $\mathrm{H}$. Squamous cell carcinoma in the renal pelvis of a horseshoe kidney. International Journal of Urology, 2004; 11: 782-784.

9. Sahoo TK, Das SK, Mishra C, Dhal I, Nayak R, Ali I, Panda D, Majumdar SK, Parida DK. Squamous cell carcinoma of kidney and its prognosis: a case report and review of the literature. Case Reports in Urology. 2015; 2015: Article ID 469327

10. Berz D, Rizack T, Weitzen S, Mega A, Renzulli J, Colvin G. Survival of patients with squamous cell malignancies of the upper urinary tract. Clin Med Insights Oncol. 2012;6:11-18.

11. Nativ O, Reiman HM, Leiber MM, et al. Treatment of primary squamous cell carcinoma of the upper urinary tract. Cancer. 1991; 68: 2575-2578.

12. Lee TY, Ko SF, Wan YL, Cheng YF, Yang BY, Huang DL, et al. Renal squamous cell carcinoma: CT findings and clinical significance. Abdom Imaging. 1998; 23: 203-08.

13. Kalayci OT, Bozdag Z, Sonmezgoz F, Sahin N. Squamous Cell Carcinoma of the Renal Pelvis Associated with Kidney Stones: Radiologic Imaging Features with Gross and Histopathological Correlation. Journal of Clinical Imaging Science. 2013; 3: 14

14. Bhaijee F. Squamous cell carcinoma of the renal pelvis. Ann Diagn Pathol. 2012; 16: 124-27.

15. Mardi K, Kaushal V, Sharma V. Rare co-existence of keratinizing squamous cell carcinoma with xanthogranulomatous pyelonephritis in the same kidney: Report of two cases. J Cancer Res Ther. 2010; 6: 339-41.

16. Attalla K, Haines K, Labow D, Mehrazin R. Squamous Cell Carcinoma of the Renal Pelvis: Atypical Presentation of a Rare Malignancy. Urology Case Reports. 2017; 13: 137-9. 